\title{
INEFICACIA DE LA ACCIÓN DE REPETICIÓN
}

\author{
INEFFECTIVE ACTION REPLAY
}

\section{Guillermo Enríquez Burbano*}

Resumen: La presente investigación abarca el estudio de la acción de repetición, comprendida en el art. 11.9 de la Constitución de la República, cabe destacar que la norma suprema plasma el principio o derecho del Estado a la indemnización por daños provocados por servidores públicos cuyo accionar marcado por la intencionalidad o dolo hayan provocado el mismo. Se verifica la inexistencia de un procedimiento específico y efectivo a través del cual se demande la acción de repetición, lográndose por consecuencia la correspondiente sentencia ejecutable, situación que avoca al planteamiento de nuevos elementos al procedimiento presente. La actual regulación de la acción de repetición garantiza que los jueces que conocen las causas no puedan emitir un pronunciamiento sobre dolo o culpa grave de los funcionarios o servidores públicos, o determinar el grado de responsabilidad de los mismos, de ahí que sea preciso lograr una determinación efectiva del responsable para que pueda responder por los montos indemnizatorios que se derivan de las sentencias internas e internacionales cuando el Ecuador debe asumirlos, tal situación se traduce en una pérdida económica para el erario público y una perpetuación de la impunidad para las acciones desarrolladas de forma irresponsable por parte de funcionarios o servidores públicos que puedan afectar a tercero. Se destaca que el Estado posee pleno derecho a repetir contra los funcionarios cuyas acciones dolosas o culposas sean demostradas legalmente, garantizándose de esta forma que los responsables asuman la cancelación de la indemnización o reparación económica.

Palabras clave: Estado, daño, culpa, dolo, responsabilidad

\footnotetext{
* Profesor de la Facultad de Derecho de la Pontificia Universidad Católica del Ecuador (Quito). enriquezburbano@gmail.com
} 
Abstract: This research includes the study of the action of repetition, within the art. 11.9 of the Constitution of the Republic of Ecuador, it is noteworthy that the supreme law embodies the principle or right of the State to compensation for damage caused by servers public whose actions marked by intent or fraud have caused it. the absence of a specific and effective procedure through which the action of repetition, consequently achieving the corresponding executable statement is demanded, a situation that calls to approach new elements to the present process is verified. The current regulation of the action of repetition ensures that judges who know the causes can not rule on intent or gross negligence of officials or public servants, and the degree of responsibility for them, hence it is necessary to achieve effective determination responsible so he can answer for the compensation amounts derived from the domestic and international decisions when Ecuador must assume them, such a situation results in an economic loss to the exchequer and a perpetuation of impunity for the actions carried out irresponsibly by officials or public servants that may affect third.

Keywords: State, Hurt, Guilt, Fraud, Responsibility

Sumario. I. Introducción. II. El Estado. III. La responsabilidad del Estado. IV. El servidor público. $V$. Entidad encargada de determinar el grado de responsabilidad del servidor público. VI. La acción de repetición en materia constitucional. VII. Dificultades para ejercer la acción de repetición en la legislación ecuatoriana. VIII. Conclusiones y recomendaciones. Referencias.

\section{INTRODUCCIÓN}

Aunque la acción de repetición se encuentra comprendida como una de las acciones jurídicas legales respaldadas por la Constitución de la República, ella no se utiliza de forma continua, pues se evidencia que la mayoría de los daños o perjuicios ocasionados por funcionarios o servidores públicos son sancionados a través de procesos administrativos, de modo que aquellos recursos destinados para la indemnización de las víctimas de tales acciones corren a cuenta del erario público.

El derecho de repetición puede abordarse como la herramienta legal destinada a garantizar al Estado su derecho de juzgar a los funcionarios públicos responsables de daños y perjuicios a la propiedad pública o privada como resultado de acciones ilícitas derivadas de la inobservancia de los parámetros legales existentes, dolo o incapacidad (Carreras, 2010). 
Castillo (2012) señala que el principal objetivo de la acción de repetición se subordina a la necesidad de lograr la recuperación parcial o total de los recursos económicos utilizados por el Estado para cancelar las indemnizaciones de los afectados, ex art. 11.9 de la Constitución. Este artículo señala que es responsabilidad del Estado la cancelación total de los daños efectuados a la propiedad pública o privada, pero acto seguido cuenta con el derecho de repetir contra los funcionarios responsables de dichas acciones, los cuales asumirán el pago de la indemnización correspondiente cancelada por el Estado.

Aguilera (2010) indica que la garantía de la repetición requiere que previamente se justifique la existencia no solo de un procedimiento, el cual dé aviso a las personas sometidas en el mismo, sino también que garantice la realización de la investigación previa en plena concordancia con lo señalado en el art. 69 de la Ley Orgánica de Garantías Jurisdiccionales y Control Constitucional (en adelante LOGJYCC). Esto implica que la administración comunicará a los servidores o funcionarios públicos del desarrollo de la acción de repetición con el objetivo de que los mismos puedan ejercer su derecho constitucional a la defensa, siguiendo el debido proceso y garantizando al mismo tiempo la precautelación de los derechos establecidos en la Constitución.

La resolución administrativa puede establecer potenciales responsabilidades. Sin embargo, con el objetivo de garantizar la operatividad de la acción de repetición, debe existir una sentencia previa expedida por la autoridad correspondiente, debidamente ejecutoriada que haya establecido la responsabilidad personal por el grado de participación en acciones $\mathrm{u}$ omisiones, de las personas a quienes ha de intentarse la repetición de los recursos económicos desembolsado por el Estado o sus instituciones para sufragar por mala prestación del servicio público, cuando esta se haya debido a culpa grave o dolo de las personas declaradas judicialmente responsables por los hechos que motivan las responsabilidad objetiva del Estado.

Delgado (2011) explica que no existirá ningún servidor público inmune o exento de responsabilidad por aquellos actos llevados a cabo en el ejercicio de las funciones propias del cargo desempeñado, tal como queda establecido en el art. 233 de la Constitución. La acción de repetición puede ser observada como el recurso legal que garantiza un mayor grado de responsabilidad de los funcionarios en el ejercicio de sus actividades.

Ha de destacarse que no hay excepciones en esto, ni por la jerarquía de los funcionarios públicos. Son absolutamente todos los funcionarios quienes están sujetos a la acción de repetición por parte del Estado, en caso 
de evidenciarse la responsabilidad de los mismos en actos ilícitos causantes de daños o perjuicios a la propiedad estatal o privada.

El art. 11.9\$2 de la Constitución de modo imperativo ordena que la acción de repetición se ejercerá «en contra de las personas responsables del daño producido», lo que significa que previamente al ejercicio de esta acción no debe existir duda de la responsabilidad que cada persona ha tenido a fin de que la repetición se ejerza sin ningún tropiezo.

Consideramos que la actual regulación de la acción de repetición no garantiza a los jueces la capacidad de pronunciarse sobre el dolo o culpa grave de los funcionarios o servidores públicos; no se puede determinar con exactitud el grado de responsabilidad de los mismos en el daño ocasionado. Esta situación conlleva a que no exista una garantía de determinar a quién corresponderá la cancelación de los montos económicos entregados por concepto de indemnización a las víctimas, debiendo el Estado cancelar los mismos en perjuicio del erario público.

Ello hace que el derecho de repetición en Ecuador no se ejerza con efectividad. La normativa prevé que el funcionario responsable (máxima autoridad) debe dar inicio a dicha acción. Al verificarse la reincidencia en dicha problemática, por no existir una disposición determinada a través de la cual se logre establecer a quien corresponde la facultad de determinar la responsabilidad, se torna imprescindible el establecimiento de un conjunto de parámetros a través de los cuales las autoridades de las instituciones vinculadas con el daño (las que hayan debido asumir la cancelación de la indemnización a las víctimas) lleven a cabo la acción de repetición como una obligación irrenunciable - y no potestativa - en contra de aquellos servidores o funcionarios responsables.

La actual indeterminación del grado de responsabilidad del funcionario público se debe, en gran medida, a que la LOGJYCC no respeta lo establecido por la Constitución, que otorga a la Contraloría General del Estado la potestad de determinar el grado de responsabilidad de los funcionarios públicos, mientras que dicha ley plantea la demanda y juzgamiento con la presunción de culpabilidad.

Cuando se irrespeta la supremacía de la norma constitucional, se genera una contradicción legal entre la LOGJYCC y la Ley de Contraloría General del Estado. Esto permite una vulneración al debido proceso, pues debido a la presunción de responsabilidad se juzga al funcionario público, impidiéndole al mismo ejercer su derecho a la defensa, lo cual genera una nueva violación de derechos que eventualmente puede generar un nuevo deber de indemnizar.

En la misma línea de argumentación, Salgado (2010) afirma que se encuentra otra contradicción importante, la misma que se da mediante la 
forma de identificar a los presuntos responsables. De acuerdo con la LOGJYCC, se debe realizar mediante un informe previo que debe realizar una comisión conformada por miembros de la misma institución; en cambio, la Ley Orgánica de la Contraloría General del Estado señala que la determinación de responsabilidades se realizará a través de una auditoría interna realizada por terceros neutrales (funcionarios de la contraloría).

Lo expuesto permite la impunidad del funcionario público y facilita nuevas violaciones de derechos, no solo al juzgar en base de presunción de responsabilidades, sino al permitir que no sean juzgadas a personas que tuvieron responsabilidad intelectual, pero que al no ser ejecutores del hecho no son juzgadas.

\section{EL ESTADO}

El Dr. Toledo en su libro Pensamiento político de la antigüedad hasta la modernidad (2011), explica que el Estado se define como la estructura organizacional que desde el punto de vista político, social y económico está sustentada en un conjunto de instituciones, cuya función principal es la de lograr una relación de armonía que responda a las necesidades históricas y sociales del momento. El Estado es la resultante de un orden social que viabiliza el desarrollo humano y permite un control efectivo de varios aspectos de la vida cotidiana, como la economía, la política y las relaciones entre naciones.

Por su parte el Dr. Arguedas (2012, p. 59), señala:

«El Estado tuvo sus cimientos en las antiguas civilizaciones mesopotámicas, egipcias, indias y china, en las cuales de ningún modo se abordaban los aspectos y características actuales del Estado sino que se hacía referencia a intereses comunes y patrones raciales que lograban agrupar entorno a una figura dirigente al pueblo».

Tal tipo de pensamiento quedaba plenamente manifiesto en la cultura egipcia, la cual sobrevivió mientras mantuvo su identidad religiosa y cultural, así como su simetría racial. Una de las principales causas por las que desapareció esta civilización, tras vivir milenios de esplendor y desarrollo, fue la infiltración progresiva de nuevas culturas y razas que minaron la identidad cultural, política y religiosa que cimentaba al imperio.

Aún pueden observarse los jeroglíficos egipcios en los que se hacía alusión a las características raciales y religiosas que caracterizaban al pueblo egipcio, llamándolo a la lucha contra los invasores hititas durante el reinado del Faraón Ramsés III, para defender el Estado del faraón. 
Historiadores como Sánchez (2011) afirman que el origen del Estado no posee sus raíces en la antigua Grecia, sino en las tribus semíticas Caldeas asentadas en la antigua Mesopotamia en el primer milenio antes de Cristo, que crearon las bases de la democracia esclavista conocida posteriormente en la antigua Grecia y Roma.

En la antigua Mesopotamia, hace 2600 años, los caldeos lograron una estructura estatal capaz de dirigir todos los aspectos políticos y sociales de su civilización. El eje neural de dicho Estado fueron los sacerdotes y los militares. Se afianzó una estructura estatal en la simetría racial, la cual una vez permeada trajo como consecuencia el resquebrajamiento de dicha institución y la posterior caída del imperio caldeo babilónico en manos de los Asirios.

El historiador Portillo (2013, p. 124) explica que «epopeyas como el Mahbharata y el Ramayana hacen referencia a la creación del Estado Indio antiguo, centrándose en que el mismo se ha había plasmado a partir de la religiosa y cultural reflejada en héroes, semidioses y divinidades». Tales deidades, héroes míticos y personajes históricos del período Védico o de la civilización Hindú, en sus intercambios crean una cultura homogénea extremadamente ligada a un sentimiento religioso y cultural, a partir del cual se formaron instituciones representativas de la sociedad de la época capaces de gobernar sus propios destinos políticos y religiosos.

\section{LA RESPONSABILIDAD DEL ESTADO}

La responsabilidad estatal abarca el conjunto de obligaciones inherentes al mismo que garantiza el funcionamiento social y de sus instituciones. Por principio, todo daño causado al Estado debe ser reparado. Según Zanovini (2010, p. 86):

«La responsabilidad del Estado engloba la necesidad de proyectar igualdad de condiciones ante la ley para todos sus ciudadanos, garantizándose el cumplimiento de todas aquellas obligaciones que posean un carácter legal, así como aquellas obligaciones extracontractuales de las cuales se derive un daño o afección a terceros».

La responsabilidad del Estado se determina a través de sus actos de gestión y autoridad, existiendo un mayor control sobre los actos de gestión que sobre los de autoridad, porque los actos de autoridad generalmente son desempeñados de manera individual por funcionarios estatales.

Espinoza (2012) señala que la responsabilidad estatal está claramente estipulada en el derecho público, el cual consigna que todos aquellos daños 
ilegítimos causados a ciudadanos deben ser íntegramente reparados por las diferentes estructuras estatales, traspasando las obligaciones y responsabilidades del Estado a nivel internacional, debiendo asumir el castigo y reparación de los responsables de violaciones de sus ciudadanos.

Las responsabilidades del Estado se enmarcan en el cumplimiento del Estado de Derecho o conjunto de disposiciones legales que garantizan el adecuado desempeño y desarrollo de la nación desde el punto de vista económico, político y social, destacando la responsabilidad civil que a su vez puede ser contractual o extracontractual.

La responsabilidad civil del Estado, de acuerdo al tratadista Mauricio Hidalgo, «abarca el conjunto de obligaciones legales que aseguran los derechos básicos que regulan y rigen el desarrollo social, económico y político de la nación» (2008, p. 124). Es de destacar que tales aspectos legales garantizan el estado de derecho y el respeto pleno a las regulaciones legales y constitucionales.

Esta responsabilidad civil abarca los ámbitos administrativos, jurídicos y legislativos garantizando el Estado de Derecho. Implica también el total respeto a los derechos humanos básicos de los ciudadanos.

Marín explica que «la responsabilidad civil del Estado puede ser subdivido en facetas como el Estado Legislador, Estado Juzgador y Estado Administrativo, las cuales actúan como plataforma legal y funcional de las garantías sociales y políticas existentes en la actualidad» (2010, p. 84). Dichas facetas garantizan el correcto desenvolvimiento del Estado constitucional de Derecho.

Hay una íntima relación entre la responsabilidad civil del Estado y el Estado de Derecho. Esta se materializa en aquellas normas jurídicas que regulan consciente y adecuadamente el comportamiento de los individuos en sociedad, garantizando la prevalencia de intereses comunes, y, al mismo tiempo, el respeto a los derechos individuales; así se logra un equilibrio que favorece de forma igualitaria a todos los ciudadanos, siendo ese el elemento clave de la responsabilidad civil del Estado.

En conclusión, la responsabilidad del Estado emana de compromisos y obligaciones legales respaldadas desde el punto de vista jurídico, de tal forma que de no llegarse a cumplir existirán consecuencias jurídicas que sancionarán la violación de dichas regulaciones.

\section{EL SERVIDOR PÚBLICO}

El servicio público garantiza la funcionabilidad de los diferentes Ministerios del Estado, estableciendo una relación de proporcionalidad 
entre los recursos aportados por los contribuyentes y el servicio recibido para garantizar la salud, educación, seguridad y bienestar social en general. De ahí la importancia del servicio social como elemento imprescindible para el mantenimiento de la sociedad moderna.

El profesor de la Universidad de Zaragoza, Delgado (2014), afirma que se define al funcionario público como la persona que desempeña responsabilidades sociales dirigida por un Ministerio del Estado, siendo su actividad esencial garantizar el correcto funcionamiento social; con él se crea una dependencia y una relación entre su desempeño y el bienestar que el Estado pueda proporcionar a sus ciudadanos.

Para Castillo (2012) el empleado público pude ser definido como toda aquella persona que se desempeña laboralmente en instituciones estatales, llevando a cabo actividades derivadas de las decisiones de funcionarios públicos, los cuales poseen plena capacidad para tomar decisiones. Sin embargo, el empleado público -a diferencia del funcionario - no posee dicha capacidad de decisión, circunscribiéndose su acción a la ejecución de las disposiciones tomadas por funcionarios públicos. Por eso, las acciones que pueda llevar a cabo y perjudicar a la propiedad estatal o privada serán sujetas solamente a medidas disciplinarias a ser tomadas por los funcionarios de la entidad en la cual se desempeña.

Para Fiorini (2009) de la misma forma se garantiza que el Estado asuma la total indemnización de las víctimas de daños derivados del incorrecto desempeño de los funcionarios públicos. En aquellos casos en los que la causa generadora de la responsabilidad se deriva de la acción estatal (en el campo de la función administrativa), la reparación se subordinará a los principios del derecho público o derecho administrativo. Ha de considerarse que el funcionamiento inadecuado de la administración podrá darse por acción u omisión, tanto por la actividad legislativa, como por la judicial.

La reparación debe poseer un carácter integral cuando la actividad ilegítima es responsabilidad del Estado o sus representantes. Cabe señalar que el derecho público se subordina a la necesidad de lograr un equilibrio entre las diversas acciones de instituciones públicas que pueden afectar propiedades o intereses privados, de modo que de los daños derivados de dichas acciones deban ser asumidos por el Estado.

El objetivo de resarcir el perjuicio cometido se basa en la necesidad de garantizar el principio de igualdad y el cumplimiento de la actividad del Estad,o basado en el desarrollo de actividades que garanticen el bien común, siendo la justicia el vehículo indicado para tal accionar. 


\section{ENTIDAD ENCARGADA DE DETERMINAR EL GRADO DE RESPONSABILIDAD DEL SERVIDOR PÚBLICO}

El art. 211 de la Constitución señala que la Contraloría General del Estado es el órgano rector en los aspectos referidos al control y manejo de los recursos estatales, encargado de garantizar su correcta utilización. Con lo cual, ella puede determinar la responsabilidad del funcionario público que causó un daño en perjuicio de un ciudadano.

Por otro lado, el art. 5.1 de la Ley Orgánica de la Contraloría General del Estado, indica que los servidores públicos sin excepción deben responsabilizarse y rendir cuenta pública sobre el ejercicio de sus funciones. Y el art. 38 de esta misma ley reafirma el papel rector de la Contraloría como organismo capaz de declarar legítimas o ilegítimas las operaciones o actividades realizadas por los servidores públicos.

El artículo siguiente establece que la Contraloría General, mediante el análisis de la auditoría gubernamental realizada después de la presentación de la denuncia de la institución pública, posee la potestad de determinar las responsabilidades administrativas y civiles culposas o dolosas e indicios de responsabilidad penal, de los funcionarios públicos.

A continuación el art. 40 explica que todo funcionario público que no actuare con diligencia y empeño deberá responder por sus acciones $\mathrm{u}$ omisiones, y el art. 41 señala que ningún servidor o empleado público eximirá su responsabilidad por acatar órdenes superiores, siendo su derecho el objetar por escrito, de tal forma que se evidencie la existencia de una inconformidad con tal acción u omisión, para de esta forma no ser responsable subsidiario.

Luego el art. 45 señala que la responsabilidad administrativa culposa de los servidores y empleados públicos será determinada una vez analizados los informes y documentos presentados por la institución a la que pertenece el funcionario público, así como los documentos y demás elementos recopilados por la Contraloría en la auditoría gubernamental, en los que se pueda evidenciar el grado de inobservancia, dolo o culpa del funcionario público.

A su vez, el art. 134 de la Ley Orgánica del Servicio Público especifica que aquellas autoridades pertenecientes a entidades de la Función Ejecutiva del Estado cuyas acciones comprometan recursos económicos, en violación a las políticas y resoluciones establecidas por el Ministerio de Relaciones laborales, serán sancionadas con la destitución y serán responsables personal y pecuniariamente por los daños ocasionados. Esto no irá en perjuicio de las responsabilidades administrativas, civiles y 
penales, siendo derecho de las entidades del Estado aplicar el proceso de repetición contra los servidores responsables.

La Disposición General 23 de la Ley Orgánica del Servicio Público establece que aquellas autoridades y funcionarios que durante el ejercicio de sus funciones públicas fuesen responsables de daños al interés público o a terceros serán responsables administrativa, civil y penalmente. Luego se indica que las acciones a ser llevadas a cabo en contra de las autoridades y funcionarios responsables de daños o perjuicios serán sustanciadas en una de las Salas de los Distrital de lo Contencioso Administrativo, haciéndose efectivo el derecho de repetición del Estado contra el funcionario responsable, con la finalidad de restituir los bienes aportados por el mismo a los perjudicados.

\section{LA ACCIÓN DE REPETICIÓN EN MATERIA CONSTITUCIONAL}

La LOGJYCC aborda los diferentes aspectos legales que abarcan la responsabilidad y repetición en el art. 20. Señala que en aquellos casos en los que se demuestre la responsabilidad estatal, la autoridad remitirá a la entidad competente el expediente con la finalidad de tomar medidas administrativas en plena concordancia con lo planteado en el art. 43 de la Ley Orgánica del Servicio Público, que permite sancionar con: a) amonestación verbal; b) amonestación escrita; c) sanción pecuniaria administrativa; d) suspensión temporal sin goce de remuneración; y, e) destitución.

De verificarse conductas tipificadas como delitos, se procederá a remitir el expediente a la Fiscalía con la finalidad de tomar las acciones pertinentes. Cuando no se verifique la identidad del funcionario responsable del daño a la propiedad pública o privada, se remitirá el expediente a las autoridades públicas correspondientes, de modo que se logre determinar la identidad del responsable y su grado de participación.

El capítulo X referido a la Repetición contra servidoras y servidores públicos por violación de derechos, detalla en el art. 67 que la repetición en contra de servidores públicos y judiciales derivada de la violación de derechos en ejercicio de sus funciones. Se destaca la obligación del Estado de reparar tales acciones a través de una indemnización a las víctimas, y se especifica que la acción de repetición será llevada a cabo en contra de los servidores responsables en un periodo no superior a los tres años desde el momento en que el Estado realizó el pago de la compensación a las víctimas, período después del cual la acción prescribirá. 
El mismo art. 67 detalla el objetivo de la acción de repetición: la recuperación de los recursos económicos cancelados a las víctimas de acciones dolosas o culposas de funcionarios públicos. Se especifica del mismo modo que la acción de repetición es inherente al Estado, tomándose en cuenta la relación de dependencia que se establece entre el Estado, los funcionarios y empleados públicos, percibiéndose las acciones de los mismos como un reflejo de la institución a la cual pertenecen. De ahí que el Estado asuma la cancelación de la indemnización a las víctimas y posea pleno derecho para repetir en contra de los responsables.

El art. 1 de la Resolución 56/83 del 12 de diciembre del 2001, que trata de la responsabilidad estatal por hechos internacionales, señala que el Estado posee responsabilidad por sus hechos internacionalmente ilícitos; todo hecho internacional ilícito genera responsabilidad internacional.

Los hechos o acciones ilícitas cometidas en territorio extranjero por parte de los Estados pueden estar basados en una o varias acciones u omisiones, o la combinación entre las mismas. La existencia de hechos internacionalmente ilícitos está condicionadas por elementos como el lugar en el que se llevan a cabo, la naturaleza de la obligación que presuntamente se violó y las condiciones que verifican el hecho y justifican la naturaleza de la obligación violada.

La LOGJYCC en su art. 67 determina que el Estado posee la obligación de reparar materialmente aquellos daños ocasionados por acciones ilícitas de funcionarios o servidores públicos que actuaron con dolo o culpa grave, a través de sentencia o auto definitivo en un proceso de garantías jurisdiccionales, sentencia o resolución definitiva de un organismo internacional de protección de derechos.

El art. 68 del mismo cuerpo legal recalca el derecho de todo ciudadano de poner en conocimiento del Procurador General de la existencia de sentencia, auto definitivo o definición de organismos internacionales que ratifiquen la necesidad de reparación material.

Por su parte el art. 70.a) de dicha Ley indica que el encargado de reafirmar que aquellas sentencias o auto definitivos en procesos de garantías jurisdiccionales, sentencia o resolución definitiva de organismos internacionales de protección de derechos, en la que se plasme la orden de reparación material del Estado, deber adjuntarse a la demanda a ser presentada en la Corte Constitucional. 


\section{DIFICULTADES PARA EJERCER LA ACCIÓN DE REPETICIÓN EN LA LEGISLACIÓN ECUATORIANA}

Para llevar a cabo el ejercicio de la acción de repetición existe un conjunto de dificultades que no permiten que la misma se desarrolle correctamente.

En primer lugar, la acción de repetición debe iniciarse con un informe previo, el cual será realizado por la máxima autoridad de la institución pública que fue declarada responsable y obligada a pagar la indemnización al perjudicado. Este informe en muchas ocasiones es presentado sin determinar la identidad de los responsables, debido a que la autoridad responsable no logra esclarecer los hechos por falta de pruebas, o porque hay encubrimiento entre compañeros o porque es la máxima autoridad la que cometió el hecho ilegítimo. Esto parece haber sucedido en el juicio $\mathrm{n}^{\circ}$ 17811-2013-15969 que siguió el Ministerio de Relaciones Exteriores y Movilidad Humana y la Procuraduría General del Estado contra A.P.N.G., en la cual se rechaza la demanda porque se debía cumplir como requisito legal sustancial una investigación previa a la interposición a la demanda, con el objeto de determinar la identidad de los presuntos responsables de la entrega de una determinada camioneta a una persona distinta a su dueño. Al omitirse esta investigación previa se incurrió en violación al debido proceso. Así, la acción de repetición está condenada al fracaso. Al desconocerse la identidad de los responsables, la acción no podrá finalizar con éxito.

En segundo lugar, el problema es del juez. El juez que recepta la demanda inicial en la que se reclaman indemnizaciones por la violación de un derecho por parte de los funcionarios públicos, no posee la facultad para determinar en sentencia que ha existido culpa grave o dolo en las actuaciones de los funcionarios públicos.

La acción de repetición posee una su naturaleza retributiva de contenido económico y cumplimiento obligatorio. Por ello, cuando se verifica un daño y se condena contra el Estado, se califica la como acción civil. Luego, es responsabilidad de la Contraloría General del Estado determinar la responsabilidad del funcionario público tal como lo señala el art. 39 de la Ley Orgánica de la Contraloría General del Estado. Todo esto se puede evidenciar en el informe de investigación previa del Instituto Ecuatoriano de Seguridad Social, hecho en el ejercicio de la acción de repetición del pago dispuesto por la Corte Constitucional para el periodo de transición, por el pago efectuado al Hospital de las Fuerzas Armadas como resultado de la atención médica del jubilado M.E.A.P. En el numeral 6 se expresa que no es competencia interna del IESS determinar 
responsabilidades y/o responsables, razón por la cual el juicio fue rechazado. Esto se fundamentó en el criterio de la Jueza del Tribunal Contencioso Administrativo, según el cual el juicio de repetición es un juicio de ejecución y no de conocimiento, y al no establecerse el grado de responsabilidad de los médicos involucrados no cabe ejecutar el monto a ser repetido.

Actualmente la Contraloría General del Estado no realiza ninguna auditoría gubernamental que permita determinar de forma clara el grado de responsabilidad que posee el funcionario público, careciéndose de un juicio, auditoria gubernamental o sumario administrativo en el que se decida sobre la responsabilidad del agente causante del perjuicio, una vez declarada la responsabilidad patrimonial del Estado.

De ahí que el juez sea incapaz de declarar sentencia de repetición sobre los funcionarios responsables, dado el desconocimiento de la identidad o del grado de responsabilidad. Estos elementos obstaculizan y dificultan la ejecución de sentencias, porque las mismas deben basarse en evidencias materiales, deben contar con el informe previo entregado por instituciones públicas, a más de ser necesaria la intervención de la Contraloría General.

\section{CONCLUSIONES Y RECOMENDACIONES}

\section{Conclusiones}

1. Resulta claro que es deber del Estado garantizar y precautelar los derechos fundamentales de los ciudadanos, tal y como consta en el art. 3.1 de la Constitución, que coincide con lo planteado en el art. 9.11 del mismo cuerpo que señala que «el más alto deber del Estado, consiste en respetar y hacer respetar los derechos garantizados en la Constitución».

2. El derecho de repetición constituye una garantía al cumplimiento del principal derecho del Estado dado por lograr un respeto efectivo de los derechos constitucionales. La acción de repetición es obligatoria contra funcionarios o servidores públicos de cuyas actividades culposas o dolosas se deriven daños a particulares que deberán ser indemnizados por el Estado; de ahí se desprende el derecho del mismo de repetir contra los funcionarios públicos responsables.

3. A pesar de contemplarse la acción de repetición en la normativa nacional, no se verifica como una acción legal que se lleve a cabo con frecuencia. Al contrario, los daños derivados de un mal desempeño de funcionarios o servidores públicos se les da resolución en su totalidad a través de procesos administrativos que evitan utilizar la acción de 
repetición (aunque esta es la única herramienta legal que garantiza que los recursos económicos desembolsados por concepto de indemnizaciones de acciones que causaron juicios a terceros por actos cometidos con dolo o culpa u omisión por parte de funcionarios o servidores públicos). A la final, la indemnización será completamente asumida por el erario público.

4. El derecho de repetición se revela como la herramienta legal a partir de la cual el Estado garantiza el juzgamiento de funcionarios o servidores públicos, cuya actuación irresponsable haya sido la génesis de daños o perjuicios a la propiedad pública o privada. Tales acciones serán el resultado de la inobservancia por dolo o incumplimiento de los parámetros legales existentes.

5. El Estado posee pleno derecho a repetir contra los funcionarios cuyas acciones dolosas o culposas sean demostradas legalmente. Esto debería garantizar que los responsables se hagan cargo de la indemnización o reparación económica, lográndose de esta forma recuperar los recursos económicos desembolsados por el Estado a las víctimas de las acciones u omisiones de dichos funcionarios. Tal acción debería ejecutarse sin perjuicio de las responsabilidades penales, civiles o administrativas, siendo la Contraloría General del Estado la única entidad encargada de determinar el grado de responsabilidad de los servidores públicos.

\section{Recomendaciones}

1. Es preciso la creación de un procedimiento en sede jurisdiccional que regule específicamente la acción de repetición, teniendo en cuenta las alternativas necesarias en relación con los problemas de congestión de la justicia, además de la escasez de los operadores del Derecho, circunstancias todas que dificultan el objeto final del derecho de repetición (que es recuperar aquello que el Estado desembolsó por el actuar de los servidores o funcionarios públicos).

2. El Estado debe respetar, proteger y promover el bien común y los derechos constitucionales de los ciudadanos. La Constitución responde a esta finalidad señalando en su texto como deber primordial del Estado el asegurar la vigencia efectiva de estos derechos (art. 3.1), lo cual concuerda al reconocer que «el más alto deber del Estado, consiste en respetar y hacer respetar los derechos garantizados en la Constitución» (art. 11.9).

3. El profesor Salgado (2010), indica que la expresión de "derechos fundamentales" hace referencia a aquellas cualidades o valores esenciales y permanentes del ser humano que son objeto de protección jurídica. Es el Estado, entonces, el llamado a crear ese sistema de protección jurídica por la cual se dé efectiva vigencia a esos valores esenciales e inquebrantables 
del hombre, de respeto, protección y promoción de derechos, que pueden ser vulnerados por la misma actividad estatal.

4. Para limitar el poder del Estado y así proteger los derechos de las personas existe la separación de poderes: un Ejecutivo que gobierne y administre, un Legislativo que legisle y fiscalice, un Judicial que administre justicia y un Poder difuso que controle, con un carácter interorgánico e intraorgánico. Así el poder controla al poder dentro del mismo ordenamiento jurídico.

\section{REFERENCIAS}

Aguilera, M. (2010). Teorías compensatorias del Estado. Asunción: Luman.

Arboleda, T. (2010). La Responsabilidad del Estado. Madrid: Cervantes.

Arguedas, J. (2012). Formación de una cultura nacional indoamericana. Ciudad de México: Siglo XXI.

Carreras, D. (2010). Derechos propios del Estado. Santiago de Chile: Universidad Santa María de Chile.

Castillo, R. (2012). El servidor público español. Madrid: Cervantes.

Delgado, E. (2011). La indemnización como derecho universal. Caracas: Macmillan.

Delgado, F. (2014). Funciones y funcionarios del Estado. Zaragoza: Océano.

Espinoza, L. (2012). Funcionamiento de la Administración Pública. Ciudad de México: Azteca.

Estrada, R. (2010). Responsabilidad del Estado. Madrid: Zabalia.

Ferrero, M. (2010). Historia evolutiva del derecho. Puerto Barrios: Editorial Oscar de León Palacios.

Fiorini, B. (2009). Relación entre los actos de autoridad y la responsabilidad parcial del Estado. Buenos Aires: Palermo.

Guerrero, J. (2012). La responsabilidad Extracontractual del Estado. Ciudad de México: Trillas.

Gutiérrez, C. (2008). Los derechos humanos y las responsabilidades del Estado. Buenos Aires: Universidad de Palermo.

Hidalgo, M. (2008). Apuntes de Derecho Administrativo ecuatoriano: Teoría y Práctica. Quito: País.

Linares, J. (2010). La responsabilidad civil del empleado público. Ciudad de México: Estudios legales.

Marín, M. (2010). Fundamentos del cosntitucionalismo. Manizales: Universidad de Caldas: Ciencias Jurídicas. 
Marin, M. (2011). La indemnización por daños y perjuicios. Universidad de Caldas: Manizales.

Mariño, T. (2011). El derecho administrativo. Bogotá: Patria.

Padilla, A. (2012). La Responsabilidad del Estado. Madrid: Océano.

Portillo, L. (2013). Organización política de la Cultura Hindú. Barcelona: Gran Angular.

Rivera, G. (2010). Derecho de reparación integral. Montevideo: Caspilla.

Rodríguez, A. (2011). Perpectivas de las mutualistas en latinoamerica. Santiago de Chile: Sociedad.

Salgado, J. (2010). Los derechos indemnizables y su compensación. Aconcagua: Océano.

Sánchez, P. (2011). La responsabilidad contractual del Estado. Quito: Colap.

Toledo, J. (2011). Pensamiento político de la antigüedad a la modernidad. Buenos Aires: Ceal.

Vallejo, R. (2013). La responsabilidad del servidor público. Ciudad de México: Trillas.

Vonlineur, L. (2014). Sistemas Mutuales. Paris: Rouge Mark.

Zanovini, G. (2010). Derecho Administrativo. Ciudad de México: Azteca. 